Bryant University

Bryant Digital Repository

\title{
A Collaborative Project to Increase the Participation of Women and Minorities In Higher Level Mathematics Courses
}

Kristin Kennedy

Bryant University

Phyllis Schumacher

Bryant University

Follow this and additional works at: https://digitalcommons.bryant.edu/math_jou

\section{Recommended Citation}

Kennedy, Kristin and Schumacher, Phyllis, "A Collaborative Project to Increase the Participation of Women and Minorities In Higher Level Mathematics Courses" (2005). Mathematics Department Journal Articles. Paper 53.

https://digitalcommons.bryant.edu/math_jou/53

This Article is brought to you for free and open access by the Mathematics Department Faculty Publications and Research at Bryant Digital Repository. It has been accepted for inclusion in Mathematics Department Journal Articles by an authorized administrator of Bryant Digital Repository. For more information, please contact dcommons@bryant.edu. 
A Collaborative Project to Increase the Participation of Women and Minorities

In Higher Level Mathematics Courses:

\author{
KRISTIN KENNEDY \\ PHYLLIS SCHUMACHER \\ Bryant University \\ Smithfield, Rhode Island
}

\begin{abstract}
In this article, the authors describe a program developed to encourage women and minorities to continue their study of mathematics in high schools until graduation. The 3-year program was a collaborative effort by professors and students from Bryant University, local businesses, and local high schools. During the 3 years, the program evolved from the development and presentation of reality-based mathematical modules taught in the high school classrooms to an interdisciplinary enrichment activity at Bryant University. The university students acted as mentors or tutors to the high school students. Throughout the program, the business representatives, the university personnel, and the high school teachers worked in collaboration to bring mathematics alive to the students through real-world applications.
\end{abstract}

For years there has been a growing concern about the scarcity of women and individuals from ethnic minority groups in scientific and technical fields. This problem is of concern to academics and business personnel alike. According to a recent National Science Foundation report (NSF, 2000), in 1997 only $22.8 \%$ of the scientists and engineers in the labor force were women and most of these women were in the social and related sciences. Women represented only $27.3 \%$ of the computer and mathematical scientists, $21.9 \%$ of the physical scientists, and only $9.1 \%$ of the engineers. The report also indicated that $82.8 \%$ of scientists and engineers in the U.S. labor force in 1997 were White, 10.4\% were Asian/Pacific Inlanders, 3.4\% were Black, $3.1 \%$ were Hispanic, and $0.3 \%$ were American Indian/Alaskan/Other .

The statistics on recent graduates indicate that the situation is not likely to change. 
The number of bachelor's degrees conferred by degree-granting institutions in the U.S. is provided by the National Center for Educational Statistics (NCES). These statistics for 2001 graduates indicate that there has not been much improvement in quantitative fields, particularly in computer science and engineering. The NCES figures indicate that $72 \%$ of the degrees in Computer and Information Science were awarded to men with only $28 \%$ to women and only 9.7\% to Blacks, and $5.1 \%$ to Hispanics. For engineering, $79.6 \%$ of the degrees went to males and only $5.4 \%$ to Blacks and $5.45 \%$ to Hispanics (NCES, 2001).

Statistical data obtained from the College Board reports concerning the performance of women and minorities in high school mathematics and intended college majors show that these disparities start to appear in high school. The College Board (2002) site noted that there is no significant difference between the performance of women and men in high school mathematics. The reported national average grade point average (GPA) for college-bound students in 2002 was 3.08 for women and 3.09 for men (College Board). Not only do women perform as well as men in mathematics classes but also, according to the National Assessment of Educational Progress (NAEP), "In general, female students are as likely as males to take advanced math/science courses in high school with the exception of physics" ("Girls' math/science education," 1998)[p.44].

Despite the fact that women perform as well as men in mathematics courses and that they take as many advanced math courses as their male counterparts, they do not score as well on the math SAT and AP exams. According to the SAT College Board, in 2002 the average math SAT score for men was 534 whereas the average score for women was 500 . The differences between men's and women's scores have narrowed slightly since 1997. There are even greater disparities with reference to ethnic SAT data. 
Except for Asian Americans, of whom approximately $64 \%$ took physics and $42 \%$ took calculus, the other ethnic minorities lag somewhat behind Whites, particularly with respect to having taken calculus (College Board, 2002). Whereas 26\% of the White students reported having taken calculus, only $14 \%$ of the African Americans and between $14 \%$ and $19 \%$ of students from other ethnic minority groups reported having taken calculus. The College Board organization also provides the average math SAT scores for the various ethnic groups. In 2002, average scores for students of Asian descent, White Americans, African Americans, and other Hispanic minorities were, respectively, 569, 533, 427, and 464 (College Board).

Intended college major is also an important statistic to consider in determining the number of students entering technical and scientific fields. Only $18 \%$ of students nationwide expressing an interest in both computer science and in engineering as majors were female. Of those expressing an interest in mathematics, $56 \%$ were male and $44 \%$ were female. The only major in a scientific field in which a greater percentage of women expressed interest was biology, in which $66 \%$ of the intended majors were women (College Board, 2002). The NAEP findings noted that this difference begins as early as eighth grade ("Girls' math/science education," 1998). Furthermore, Oswald and Harvey (2001) noted very low percentages of women obtaining degrees in math, physical science, and engineering. In fact, they indicated that two and a half times more women leave the field than men do. They further stated that math is a "critical filter" for future careers in technological fields.

Several authors have studied the influence of high school course selection on a later choice of science and mathematics majors in college. Trusty (2002) reported that this correlation was greater for women than for men. Trusty also reported that Adelman found that the completion of a college degree was related to the level of mathematics completed in high school. 
He found that this relation held for all racial and ethnic groups and was stronger for African Americans and Hispanic students than for White students (Adelman, 1999). These researchers' data suggest that intervention efforts should be targeted at middle or high school students.

Statistics underscoring this issue have been lingering for many years. The concern is shared by business and technical colleges, which have experienced a declining enrollment of women students and a minimally growing number of other minority students. In this article, we describe a project, the Math Accelerating Professionals (MAP) Program, which was developed as part of a grant that involved the collaboration of university math professors, business professionals, and high school math teachers. General Electric funded the MAP project, to be administered at Bryant University over 3 years, and area high schools were selected for participation on the basis of the number of enrolled minority students.

The students who participated from each school were the ninth graders enrolled in advanced mathematics classes. Because high school math is a "critical filter" for those entering technological fields, we targeted for this research early math classes. Although women and minorities were the students of concern, the project was planned for the entire population in the classes of the schools participating in the program.

\section{Year 1}

The 1st year of the program had several objectives: (a) to pair each high school with a local company in its town, (b) to design a preliminary mathematical teaching module associated with a business topic, (c) to initiate a college-student mentoring program with the local high schools, and (d) to provide opportunities for social interaction of all involved parties.

The grant administrator at the university hired two former high school teachers to act as liaisons between the university, business, and high school personnel by identifying local 
companies, in the respective towns of the participating high schools that would assign company representatives to work in the program. (Kris - I think they really meant who hired them)The professors were charged with developing a classroom teaching module illustrating the importance of mathematics in the daily workings of the business world.

One of the challenges was to simplify the business applications enough so that they would be at an appropriate level for a typical ninth-grade algebra class. Because the MAP program is a 3-year program, it was important that the chosen topic would grow as the students' math ability improved. The project required a simple model representing an interesting problem that easily could be enhanced in level of difficulty and to which a computer application could be added. We chose the application of linear programming (LP). LP uses mathematical modeling, a process of changing a word problem into algebraic expressions. (The students would be familiar with this process, since it is exemplified in all text books covering LP.----I am not sure I would add this sentence since not all high school texts cover LP I - I agree let's cut this sentence.)

The modeling process is an essential skill for high school students. Furthermore, there are several computer packages available that solve LP with both a graphical and a computer algorithmic approach. The discussion of LP with the help of computer packages could be enhanced to include sensitivity analysis, which examines the effect of perturbance of the parameters of the problem on the solution.

One of the businesses coupled with a high school happened to be using LP for top-level managerial decisions. The students were impressed to see that actual data from the company could be used in the LP model that they were studying. Initially, we had them use the graphical solution method with the original data from the manufacturing company. The students 
understood the concept of graphing inequalities; however, graphing a set of inequalities and creating a convex region as a solution space was an expansion of the topic as it is traditionally presented at this level. We simplified the original data set to two variables and three constraints. However, the entire data set from the company was included as an appendix and could be used by the teacher as an optional application to be solved with a computer package.

The third facet of the grant involved the employment of university students, whose role was to act as both mentors and tutors to the high school students. During the semester, the university students visited the high school, met with the students, and tutored them in their classroom.

Early in the program, there was a formal dinner at which all the participants met socially, and at the end of the academic year the high school students and teachers came to the university for a "Meet the Professionals Day" (MPD). The MPD was a day devoted to highlighting the value of studying mathematics. Guest speakers from several businesses participated, and the students were broken into groups to attend seminars on different aspects of the importance of math to business.

\section{Year 2}

In the 2nd year, the relationships among the grant participants became significantly more relaxed and comfortable. The high school teachers and the professors worked together to clarify and enhance the mathematical modules, which were again taught in the classrooms. A significant addition to the program was visits by the professors to high schools where they addressed the students. They talked about math at the college level and about mathematics careers. Their objective was to encourage the high school students to continue their pursuit of mathematics. 
The university student-mentors now worked easily with the high school students and derived a great deal of satisfaction from not only tutoring but also sharing their success in pursuing college level mathematics. All of the student mentors, with one exception, were women who were excellent in mathematics and had chosen technical fields. The only difficult part in establishing the mentoring program was pairing all of the respective schedules.

In the early fall, a second formal dinner was held with the professors, the high school teachers, the mentor-tutors, and the business professionals. One of the highlights of the evening took place when the student mentors spoke briefly about how they chose math as a career path.

At the end of the year, there was a second and very successful "Meet the Professionals Day" similar to the first MPD. The two keynote speakers were women with outstanding résumés and experience in the business and research worlds. A sophomore class of 25 women from one of the attending high schools was very positively affected by this day of seminars. The camaraderie that developed over the 2 years was no less important to the success of the program than any other aspect of the program.

\section{Year 3}

The 3rd year was comprised of several of the same components involved in the first 2 years. There was a formal kick-off dinner, the mentor-tutor program was continued, and the year culminated with a third MPD. This year's program included two significant enhancements: (a) a professional development day for the high school faculty members and (b) a day-long enrichment program for the students. It was offered at the university in place of the classroom modules. 
The MAP program sponsored a 4-hour professional development workshop for the mathematics teachers from all of the schools involved with the program. This workshop highlighted the computer software developed by Vernier Software and Technology in conjunction with Tufts University. The teachers worked on selected mathematics activities from the Real-World Math With Computers workbook (Gastineau, Braningsen, Bower, Antinone, \& Kerner, 2003).

Of the 25 teachers who took part in the workshop, 24 completed an evaluation. Twentythree gave the day an overall rating of excellent, and 1 rated it as good. When asked if they would recommend the activity to others, 23 stated that they definitely would and 1stated that he or she probably would. When asked if they found the activity useful in applying information in the classroom, 14 found it very useful, 7 found it useful, and 3 found it somewhat useful.

At this junction, the classroom modules had been developed to their full potential. A fresh and more interactive mathematical activity for the final year seemed appropriate. Each of the high schools was invited to Bryant University for a day. Because Bryant has a new Financial Market Center and state-of-the-art technology classrooms, the enrichment day was planned around using these facilities to highlight the use of mathematics in financial applications.

The students who attended the Enrichment Day were now juniors or seniors in high school. At the beginning of the day, they gathered in an electronic classroom. Four women professors from the Mathematics and Finance Departments presented the activity for the day. The activity was designed to illustrate how some basic and familiar statistical topics generally covered in high school could be used to interpret risk and return in the financial world. The presentation opened with a review of the mean, variance, and coefficient of variation of a data set. Probability distributions were introduced with a quick coin-tossing example. As a class, the 
students created probability tables that empirically approached the theoretical distribution. The graph of this simple discrete example was an introduction to the bell-shaped curve of a normal distribution, with which the students were familiar.

The discussion then shifted to how this familiar information could be used to relate risk and return in the financial world, a topic with which the high school students were perhaps less comfortable. First, we gave an explanation of stochastic dominance, and bell- shaped curves were compared with regard to their relation to stock prices, particularly relating mean to return and standard deviation to risk. Market timing and industry returns were discussed. Then the students were given some real financial data (average company returns for 2002) to analyze. Each student had his or her own data for one particular company and used Excel to calculate his or her own mean and standard deviation. Then the students were grouped according to industry, and, collectively, they calculated the mean and standard deviations of their respective industries. A lively discussion followed concerning the performance of companies and industries in general.

The last section of the presentation developed linear regression and its application to a market model with market risk and company-specific risk. The discussion focused on how the value of beta measures the sensitivity of a company to market risk. At the end of the classroom hands-on presentation, the students visited the Financial Market Center at Bryant, where they were shown how their data was retrieved. After their tour, a representative of Fidelity Investments spoke to them about the importance of mathematics in understanding financial markets.

\section{The Assessment Information}

An important part of the grant involved the collection of data that would illustrate the success of the program to the funding institution - namely, tracking which students would 
continue with higher-level math classes. Each high school had some historical data on the dropout rate, which drove yearly changes in the class enrollment. It was challenging to establish data that clearly reflected the success of all the efforts made in the MAP program. Many factors affect high school students' decisions regarding whether to continue their mathematical studies. Notably, the MAP program had no control group within the participating schools. We provide a review of yearly changes in the enrollment numbers at the high schools.

In Table 1, we highlight the percentages of female and minority students at the schools. High Schools A and B were two schools within the same city, generally considered a blue-collar city with a population of about 70,000. High School A's population consisted of families with lower incomes, and the data in Table 1 indicate that the majority of minority students from the city attended High School A. The two schools were rather evenly split between men and women, but High School A had a significantly higher percentage of women in the MAP program than did High School B. Interestingly, High School B, which had a lower cultural diversity, a population with a higher income, and fewer minority students, had a much lower percentage of female students in the MAP program.

High School C served a population of 18,000 lower and middle-class families of a manufacturing town. Sixty percent of the town's residents are from minority groups, and many are immigrants or first-generation Americans. Therefore, we had a very high percentage (79\%) of minority students in the program. High School D serviced a city of 43,000 lower and middleclass families as well. The city is very stable, and the population is largely White; however, the education and income levels of the people are significantly below statewide levels. Both of these struggling high schools posted high percentages of women in the MAP program, compared with 
the overall percentage of women in the schools. However, the minority percentage of students from High School D in the MAP program was troublingly low.

In an effort to capture information regarding whether the MAP program was improving the overall retention rate in mathematics classes, we determined a baseline enrollment figure and a target enrollment figure. The baseline enrollment was projected by the respective high school administrations, who examined the historical data on their class sizes for the previous 5 years. The baseline was then established as the number of students expected to continue into the advanced class the following year. At some schools, this meant that the students could continue only with teacher approval.

We then established a target enrollment that would meet the goals of the original grant with General Electric. The original goal for the 1 st and 2 nd years was simply to ensure that the target enrollment would be greater than or equal to the baseline enrollment. As the program developed from year 2 to year 3, the goals became more quantitative. From year 2 to year 3 , the grant specified that the target enrollment should be greater than or equal to $105 \%$ of the baseline. After year 3, the target enrollment was to be greater than or equal to $110 \%$ of the baseline enrollment. The original grant also established the goal of trying to increase the number of students taking calculus before graduating. However, because not all of the schools offered calculus, this goal was modified to stipulate that the students should be on track to take either pre-calculus or calculus by year 3, their senior year. We present this information in Table 2.

In examining the data for year 2, we can see that the actual numbers correspond closely to the target numbers. High School D posted the lowest actual enrollment with respect to the target enrollment. A few women dropped out of the program, even though High School D had the strongest tutoring program of all. In fact, the afternoon tutoring program was usually 
attended completely by women. High School C posted very encouraging numbers, given that this high school represented the lowest income level and the lowest educational level of all four schools. For this school, the target enrollment involved simply maintaining the baseline enrollment. The numbers for the actual enrollment fell short by only one, but this is a school with much transience and problems such as high school pregnancy. To have one or two students select to go to college and study quantitative programs would be a success story from High School C.

In year 3, all of the baseline numbers dropped, so the target numbers appear low as well. The great success story was High School C. The actual enrollment was significantly higher than the target number. To motivate students to even consider taking pre-calculus in their senior year is a difficult task. High School D was also successful in maintaining the target number, which was higher than the baseline. Although High Schools A and B achieved numbers slightly lower than the target numbers, the program did not incur a high dropout rate.

For the post-graduation year, as set by the original grant, the goal of the target number was to be at least $110 \%$ of the baseline number. The data, if collected next year, will be based on the students' reporting of their choices for majors and concentrations of study as college freshmen.

\section{Conclusion}

The MAP program concluded with a third MPD. We asked all attending students to complete a questionnaire that included items concerning their likelihood of attending college and their intended major. We present these results in Table 3. As can be seen from these numbers, most students were planning on attending college. At three of the schools, more than $60 \%$ of the 
students planned on pursuing a quantitative field of study. At High School B, the percentage jumped to over $90 \%$.

In an attempt to measure the success of the program in highlighting the importance of mathematics, we asked the students to rate the extent of their agreement with the following statement: "Mathematics is important to everyone's life" (see Table 3). Astonishingly, almost $100 \%$ of the students either agreed or strongly agreed with the statement.

Overall, the numbers were encouraging. The high school students particularly liked the mentoring program and the activity days at Bryant College. For three of the four high schools, in year 3 the actual numbers of students still studying math were higher than the baseline numbers, with significant success demonstrated in High School C. The original grant with General Electric maintained that a decision to study a higher level of mathematics by only one or two more women or minority students from these four high schools would be considered a success. The goal was achieved.

\section{REFERENCES}

Adelman, C. (1999). Answers in the toolbox: Academic intensity, attendance patterns, and bachelor's degree attainment [Monograph]. (Kris 8 was the number for the reference for Paquin and Blumenthal in the last NEDSI paper do you want to include that citation or just leave this one as is?)

College Board. (2002). College bound seniors. College bound report. Retrieved September 25, 2002, from http://www.collegeboard.com/about/news info/cbsenior/yr2002/html/2002reports.html

Gastineau, J., Braningsen, C., Bower, B., Antinone, L., \& Kerner, E. (2003). Real world math with computers. Beaverlin, OR: Vernier Software and Technology.

Girls' math/science education. (1998). Education Digest, 63(5), 42-49. (I corrected the date here)

Kennedy, K., \& Schumacher, P. (under review). Increasing the participation of women and minorities in higher level mathematics courses: The first year of a collaborative project. 
National Center for Education Statistics (NCES). (2001). Digest of education statistics, Table 269. Retrieved April 29, 2003, from http://nces.ed.gov/pubs2002/digest2001/tables/dt269.asp

National Science Foundation (NSF), Division of Science Resources Studies. (2003). Women, minorities, and persons with disabilities in science and engineering: 2000. NSF 00-327.

Arlington, VA. Retrieved May 4, 2003 from

http://www.nsf.gov/sbe/ses/nsf00327/access/ch5/ch5.html

Oswald, D., \& Harvey, R. (2001). Hostile environments, stereotype threat, and math performance among undergraduate women. Current Psychology, 19(4), 338-356.

Trusty, J. (2002). Effects of high school course taking and other variables on choice of science and mathematics college majors. Journal of Counseling and Development, 80(4), 464-475. 